Article

\title{
Effect of Sodium Pyrophosphate on the Reverse Flotation of Dolomite from Apatite
}

\author{
Yanfei Chen, Qiming Feng, Guofan Zhang *, Dezhi Liu and Runzhe Liu
}

School of Minerals Processing and Bioengineering, Central South University, Changsha 410083, China; yanfeichen@csu.edu.cn (Y.C.); qmfeng@126.com (Q.F.); 155611069@csu.edu.cn (D.L.); liurunzhe@126.com (R.L.)

* Correspondence: csuguofanzhang@163.com; Tel: +86-731-88-830-913

Received: 4 June 2018; Accepted: 26 June 2018; Published: 29 June 2018

\begin{abstract}
In this study, the effect of sodium pyrophosphate (NaPP) on the separation of apatite from dolomite by flotation was systematically investigated. Flotation results revealed that NaPP could selectively depress the flotation of apatite, thus realizing the separation of apatite from dolomite. Further, the selective depression mechanism of $\mathrm{NaPP}$ was studied through zeta potential measurements, contact angle measurements, and X-ray photoelectron spectroscopy (XPS) analysis. The results demonstrated that the adsorption of sodium oleate $(\mathrm{NaOL})$ onto apatite surface was depressed by the preferential interaction of NaPP with active Ca sites. For dolomite, while the presence of NaPP hindered the interaction of NaOL with active $\mathrm{Ca}$ sites, it appeared to enhance the reactivity with active $\mathrm{Mg}$ sites. Thus, the adsorption of $\mathrm{NaOL}$ onto dolomite surface was hardly influenced. In this way, the separation of apatite from dolomite was achieved.
\end{abstract}

Keywords: sodium pyrophosphate; flotation; depression; apatite; dolomite

\section{Introduction}

Phosphorous, as one of the most common elements on earth and essential elements in organisms, is widely used in the production of fertilizers, detergents, pharmaceuticals, fluxes, cement, and many other industrial processes [1-5]. Nevertheless, with the rapid development of China's economy, the production of phosphorous cannot meet the requirement of the country [6]. Hence, the efficient exploitation of phosphate ore resource becomes more and more important. Moreover, growing demands for phosphorous have motivated the development of new technologies to concentrate phosphates from low-grade ores [7].

China has the second largest reserve of phosphate ore. However, vast majority of these resources are complex low-grade ores [8,9]. In these ores, the main valuable mineral, apatite is usually associated with gangue minerals, such as dolomite. Reverse flotation can be applied for phosphate ores that have high dolomite content [9-12]. However, there are still considerable difficulties in separating apatite from dolomite by means of reverse flotation. Furthermore, for fine-grained dissemination and complex minerals composition, apatite is often intergrown with dolomite. On the other hand, as calcium-bearing minerals, apatite and dolomite have similar surface properties. Additionally, dissolved components from apatite and dolomite will hydrolyze, precipitate, and adsorb onto the minerals [13-15]. All of these factors determine the interfacial properties of the minerals and make it more difficult to separate apatite from dolomite.

For these reasons, to separate apatite from dolomite effectively, research has focused on developing selective flotation agent. As known, fatty acids are most widely used collectors in the flotation of apatite and dolomite, and the development of novel flotation collectors has been an area of research interest. Despite successful and economic recovery of apatite via reverse flotation, the selectivity of using fatty acids and their derivatives as collectors is still not satisfactory due to their similar surface reactivity of calcium-bearing minerals such as apatite and dolomite [10,16-18]. For effective 
utilization of phosphate ore resource, it is important to selectively separate apatite from dolomite. Therefore, an effective depressant is essential for improving the floatability differences between apatite and dolomite.

Due to its extensive sources and low unit cost, $\mathrm{H}_{2} \mathrm{SO}_{4}$ has been widely used as a depressant in apatite flotation. However, large dosages of $\mathrm{H}_{2} \mathrm{SO}_{4}$ will lead to the corrosion of flotation equipment, and the production of acidic wastewater. In addition, the production of sediment $\left(\mathrm{CaSO}_{4}\right)$ could cause pipeline blocking, which cannot be appropriately resolved as yet $[8,14,19]$. Thus, the utilization of $\mathrm{H}_{2} \mathrm{SO}_{4}$ to separate apatite from dolomite remains a problem.

Sodium pyrophosphate, known as condensed phosphate, is formed by repeated condensation of tetrahedral $\left[\mathrm{PO}_{4}\right]$ units. It is usually used as water softener, emulsifier, and chelating agent. For the presence of chelating group, the addition of sodium pyrophosphate may promote the formation of metal ion-pyrophosphate, preventing its reaction with collector [20]. It was demonstrated that sodium pyrophosphate could reduce the adverse effect of serpentine on the flotation of pentlandite by shifting the slime surface charge [21]. In addition, sodium pyrophosphate has also been used in scheelite flotation [22,23]. However, there are few reports on the utilization of sodium pyrophosphate as a depressant in apatite flotation.

In this paper, sodium pyrophosphate (NaPP) was introduced as a flotation depressant to selectively separate apatite from dolomite. Micro-flotation tests were performed to reveal the selective depression of apatite by NaPP. In addition, the underlying mechanism was investigated through zeta potential and contact angle measurements, and XPS analyses.

\section{Experiments}

\subsection{Materials}

The sample of apatite was obtained from Yunnan Phosphate Chemical Group Co., Ltd. located in Yunnan, China. The ore was dry-ground in a lab-scale ball mill and then sieved to get $-74+38 \mu \mathrm{m}$ fraction for the flotation tests. In addition, a part of fine fraction $(-2 \mu \mathrm{m})$ was also obtained for the zeta potential measurements. X-ray diffraction (XRD) analyses (Figure 1) revealed that the purity of apatite sample was considerably high with a bit of quartz.

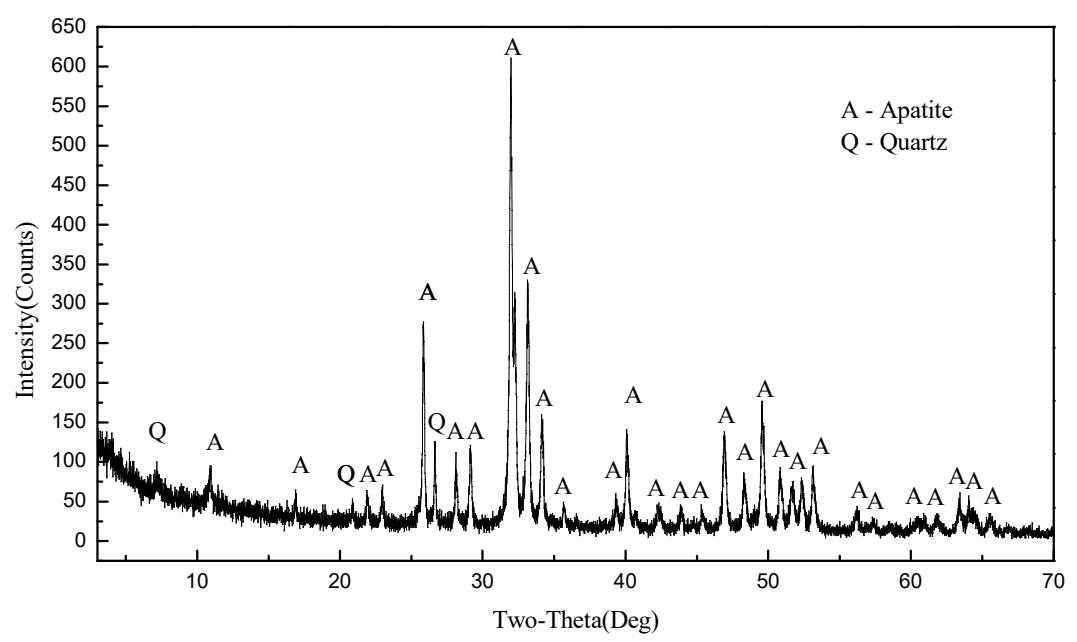

Figure 1. X-ray diffraction (XRD) pattern of the apatite sample.

The sample of dolomite was obtained from Changsha Ore Powder Factory located in Hunan, China. The ore was dry-ground in a lab-scale ball mill and then sieved to get to get $-74+38 \mu \mathrm{m}$ fraction for the flotation tests. In addition, a part of fine fraction $(-2 \mu \mathrm{m})$ was also obtained for the 
zeta potential measurements. X-ray diffraction (XRD) analyses (Figure 2) revealed that the purity of dolomite sample was very high.

Sodium pyrophosphate (NaPP) used as the depressant in this study was bought from Tianjin Yongda Chemical Reagent Development Center. Sodium oleate (NaOL) bought from Tianjin Kermil Chemical Reagents Development Centre was used as a collector. $\mathrm{HCl}$ and $\mathrm{NaOH}$ obtained from Aladdin Reagent Co. Ltd. (Shanghai, China) were used to adjust the $\mathrm{pH}$ value. All the reagents used in this study were of analytical grade. Deionized water was used for all the tests.

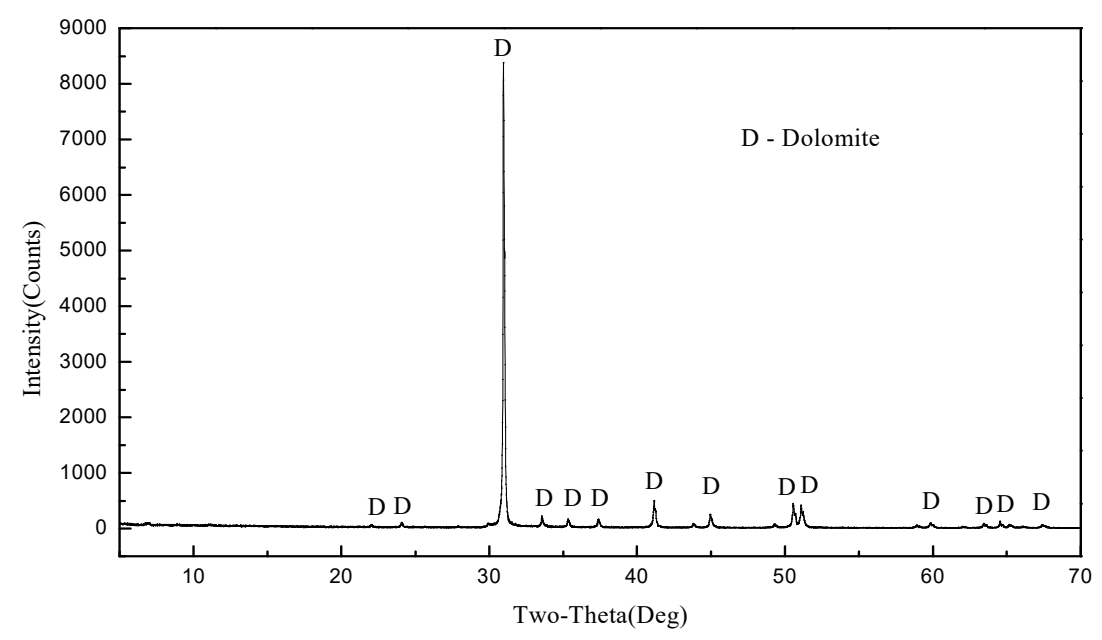

Figure 2. XRD pattern of the dolomite sample.

\subsection{Micro-Flotation Experiments}

Micro-flotation experiments were carried out in an XFG flotation machine (Exploring machinery Plant, Changchun, China) equipped with a $40-\mathrm{mL}$ cell at $2000 \mathrm{rpm}$ agitation speed. For single mineral tests, $2.0 \mathrm{~g}$ of pure mineral was placed in the flotation cell with $35 \mathrm{~mL}$ deionized water and then conditioned for $1 \mathrm{~min}$. NaPP and $\mathrm{NaOL}$ were successively added and stirred for $3 \mathrm{~min}$, respectively. The flotation process lasted $3 \mathrm{~min}$ for each test. Following this, the flotation recoveries were calculated based on the weights of concentrates and tailings.

For artificial mixed minerals flotation experiments, the mass ratio of apatite and dolomite mineral was 1:1 for binary mixture. The flotation process was the same as single mineral tests. After the flotation process, the concentrates and tailings were assayed for $\mathrm{P}$ and $\mathrm{Ca}$. The recovery of apatite was calculated based on $\mathrm{P}_{2} \mathrm{O}_{5}$ contents of concentrates and tailings.

\subsection{Zeta Potential Measurements}

Zeta potential measurements were carried out using a Zeta Plus Zeta Potential Meter (Bruker, Karlsruhe, Germany). $\mathrm{KNO}_{3}$ was used to maintain the ionic strength at $10^{-3} \mathrm{~mol} / \mathrm{L}$. Small amounts of sample below $-2 \mu \mathrm{m}$ were added to desired amounts of solution and magnetically stirred for $10 \mathrm{~min}$, and the $\mathrm{pH}$ was adjusted using $\mathrm{HCl}$ or $\mathrm{NaOH}$. The zeta potential of samples was then measured three times using a Zeta Plus Zeta Potential Meter (Bruker, Karlsruhe, Germany). The average value and the standard deviation of zeta potential were respectively calculated.

\subsection{Contact Angle Measurements}

The contact angle measurements were performed with sessile drop method using a Digidrop goniometer (GBX, Isere, France). The crystals of apatite and dolomite were embedded in resin and then polished with 500 grit, 1000 grit and 4000 grit alumina sandpapers, successively. For the measurements of minerals in the absence of NaPP, the prepared sample was immersed in a desired concentration $\mathrm{NaOL}$ solution for $15 \mathrm{~min}$. For the measurements of minerals in the presence of NaPP, the prepared 
sample was firstly immersed in NaPP solution for $15 \mathrm{~min}$ and then in NaOL solution for another $15 \mathrm{~min}$. Next, the sample was washed with deionized water and then air dried. A water droplet (about $2 \mathrm{~mm}$ in diameter) was introduced onto the sample surface, and then the contact angle results were analyzed by computer software.

\subsection{XPS Analysis}

The change of surface chemical composition of mineral samples (apatite and dolomite) pretreated with different reagents was determined by X-ray photoelectron spectroscopy (XPS). To prevent extra surface change, the samples were stored in a vacuum drier under the temperature of $25^{\circ} \mathrm{C}$. The XPS measurements were performed on a X-ray photoelectron spectrometer (PHI5000, ULVAC-PHI, Chigasaki, Japan). Firstly, chemical components of the samples were identified by survey scan. Then, high-resolution scans were conducted focusing on certain elements. Sample charging was compensated by taking the $\mathrm{C} 1 \mathrm{~s}$ peak of background hydrocarbon at $284.8 \mathrm{eV}$ as an internal standard.

\section{Results and Discussion}

\subsection{Micro-flotation Experiments}

Figure 3 shows the flotation results of apatite and dolomite as a function of NaOL dosage. It can be seen from Figure 3 that the flotation recoveries of two minerals increased with the increase of $\mathrm{NaOL}$ dosage. The recoveries of apatite and dolomite at $60 \mathrm{mg} / \mathrm{L}$ dosage $\mathrm{NaOL}$ were $80.78 \%$ and $93.6 \%$, respectively. Meanwhile, the flotation recovery of dolomite was higher than that of apatite, which implied that NaOL had a better collecting ability to dolomite. Therefore, for the better flotation performance of dolomite, reverse flotation is a proper method to separate apatite from dolomite.

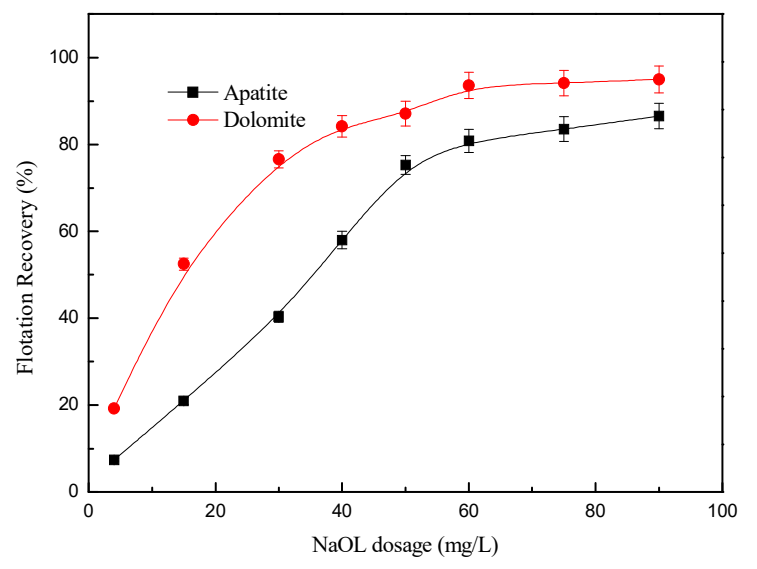

Figure 3. Effect of sodium oleate (NaOL) dosage on the flotation of apatite and dolomite.

The effect of NaPP dosage on the flotation of apatite and dolomite is shown in Figure 4. Our results with single mineral flotation show that while NaPP was an effective depressant for apatite, it had minimal effect on dolomite flotation. At a NaPP dosage of $100 \mathrm{mg} / \mathrm{L}$, apatite was nearly completely depressed while that of dolomite decreased from $93.8 \%$ to $84 \%$.

The distinct difference of the flotation recovery makes it possible to separate apatite from dolomite using NaPP as the depressant. Therefore, the flotation tests on the artificial mixed minerals were performed using NaPP as depressant. The flotation results are presented in Table 1.

As can be seen from Table 1 that, the flotation recovery of apatite was improved from $39.4 \%$ to $96.5 \%$ in the presence of $\mathrm{NaPP}$, while the recovery of $\mathrm{MgO}$ slightly increased from $11.3 \%$ to $16.3 \%$. Further, the addition of NaPP also resulted in a sharp increase of $\mathrm{P}_{2} \mathrm{O}_{5}$ grade of concentrate from $26.4 \%$ to $34.1 \%$ and a decrease of $\mathrm{MgO}$ grade of concentrate from $3.8 \%$ to $2.9 \%$. The artificial mixed minerals separation reported here suggests that $\mathrm{NaPP}$ can be used for separating dolomite from apatite. 
However, the availability of utility of this approach has to be demonstrated with "real" complex ores such as those described in the Section 1.

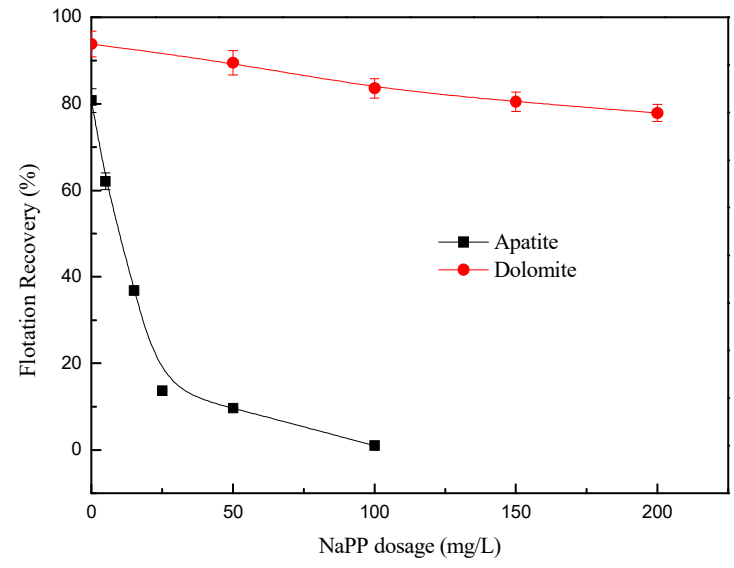

Figure 4. Effect of sodium pyrophosphate (NaPP) dosage on the flotation of apatite and dolomite.

Table 1. Artificial mixed minerals flotation results (NaOL: $60 \mathrm{mg} / \mathrm{L}$ ).

\begin{tabular}{ccccccc}
\hline \multirow{2}{*}{ NaPP (mg/L) } & \multirow{2}{*}{ Production } & Yield (\%) & \multicolumn{2}{c}{ Grade (\%) } & \multicolumn{2}{c}{ Recovery (\%) } \\
\cline { 4 - 7 } & & $\mathbf{P}_{\mathbf{2}} \mathbf{O}_{\mathbf{5}}$ & $\mathbf{M g O}$ & $\mathbf{P}_{\mathbf{2}} \mathbf{O}_{\mathbf{5}}$ & $\mathbf{M g O}$ \\
\hline \multirow{3}{*}{0} & Concentrate & 29.4 & 26.4 & 3.8 & 39.4 & 11.3 \\
& Tailing & 70.6 & 16.9 & 12.4 & 60.6 & 88.7 \\
& Feed & 100.0 & 19.7 & 9.9 & 100.0 & 100.0 \\
\hline \multirow{2}{*}{100} & Concentrate & 55.7 & 34.1 & 2.9 & 96.5 & 16.3 \\
& Tailing & 44.3 & 1.5 & 18.6 & 3.5 & 83.7 \\
& Feed & 100.0 & 19.7 & 9.9 & 100.0 & 100.0 \\
\hline
\end{tabular}

\subsection{Zeta Potential Measurements}

To reveal the underlying depression mechanism of NaPP, the zeta potential measurements of apatite and dolomite under different reagent conditions were performed as a function of $\mathrm{pH}$, and the results are shown in Figure 5a,b.
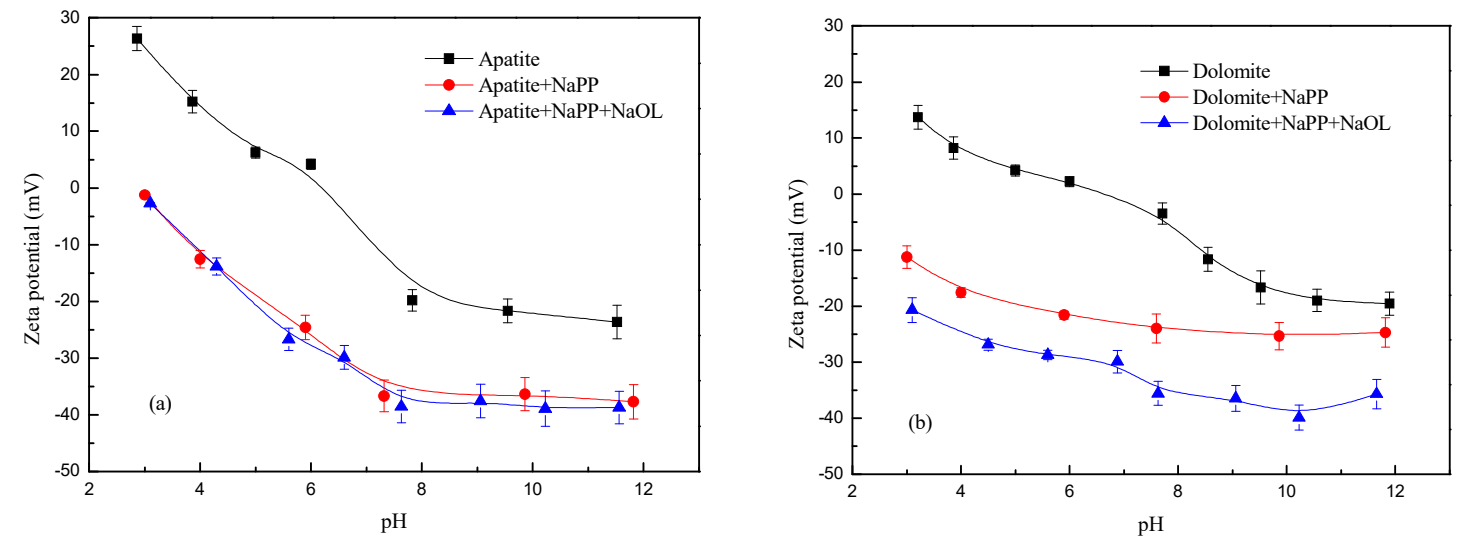

Figure 5. Effect of different reagents on the zeta potential of (a) apatite and (b) dolomite.

Comparing the data in Figure 5a,b, there were obvious potential differences which resulted in the difference in the flotation performance of the two minerals. For apatite, it was positively charged in 
the $\mathrm{pH}$ range of 3-6, which matched well with other literature. The isoelectric point (IEP) of dolomite was near a $\mathrm{pH}$ of 6.5 , which was also in agreement with the previous study $[15,24]$.

With the addition of NaPP, zeta potentials of two minerals sharply dropped over the entire $\mathrm{pH}$ range, probably due to the adsorption of dissolved NaPP components which were negatively charged. Similar shifts of zeta potentials of both minerals revealed that NaPP interacted intensively with two mineral surfaces.

When NaOL was applied after the addition of NaPP, apatite gave zeta potential which was about the same value obtained for apatite in the presence of NaPP alone. However, the zeta potential of dolomite is more negative compared with that using NaPP alone. The zeta potential results illustrated that the pre-treatment of $\mathrm{NaPP}$ prior to $\mathrm{NaOL}$ did not prevent the interaction of $\mathrm{NaOL}$ with dolomite, but hindered the adsorption of $\mathrm{NaOL}$ onto apatite surface. The zeta potential measurements results provided a preliminary understanding of the depressant effect of NaPP.

\subsection{Contact Angle Measurements}

The advancing contact angle of the two minerals before and after interaction with NaPP as a function of $\mathrm{NaOL}$ dosage was measured to reveal the changes of surface wettability of the two minerals. As can be seen from Figure 6, surface hydrophobicity of both minerals in the absence of NaPP was dramatically improved with the increase of $\mathrm{NaOL}$ dosage, which indicated the increasing adsorption of $\mathrm{NaOL}$ onto the minerals surface. In addition, the contact angle values of apatite and dolomite were in accord with the flotation recoveries presented in Figure 3. After interaction with NaPP, the contact angle of apatite was significantly decreased. However, as for dolomite, the insignificant change of contact angle showed little influence of NaPP on its surface hydrophobicity. The different effects of NaPP on the surface hydrophobicity of apatite and dolomite revealed that NaPP could restrict the adsorption of $\mathrm{NaOL}$ onto apatite while hardly affect $\mathrm{NaOL}$ adsorption onto dolomite. Therefore, the decrease of $\mathrm{NaOL}$ adsorption onto apatite resulted in the depression of its flotation performance.

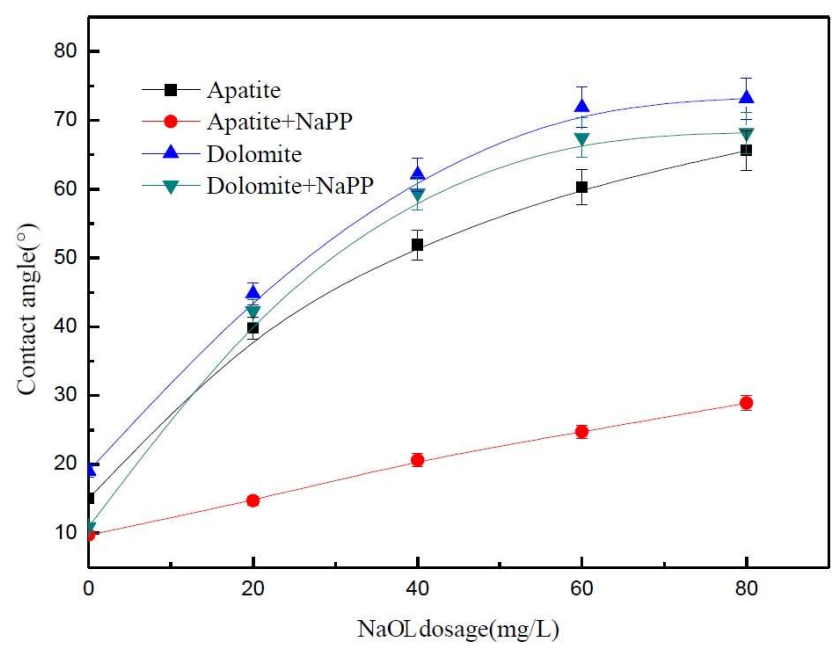

Figure 6. Contact angle of the minerals before after interaction with $\mathrm{NaPP}$ as a function of NaOL dosage.

\subsection{XPS Analysis}

To further investigate the interaction mechanism between NaPP and the two minerals (apatite and dolomite), XPS analyses of apatite and dolomite in the absence and presence of NaPP were conducted, and the fitted results are shown Figure 7. With reference to data from United States National Institute of Standards and Technology (NIST), the binding energy of $133.39 \mathrm{eV}$ and $133.80 \mathrm{eV}$ corresponds to $\mathrm{Ca}_{5}(\mathrm{PO} 4)_{3} \mathrm{~F}$ and $\mathrm{Ca}_{2} \mathrm{P}_{2} \mathrm{O}_{7}$, respectively. As can be seen from Figure $7 \mathrm{a}$, only the peak of $\mathrm{Ca}_{5}(\mathrm{PO} 4)_{3} \mathrm{~F}$ was observed in the absence of NaPP, whereas the P2p peaks could be decomposed into two P2p-P2p3/2 doublets, indicating the existence of $\mathrm{Ca}_{5}(\mathrm{PO} 4)_{3} \mathrm{~F}$ and $\mathrm{Ca}_{2} \mathrm{P}_{2} \mathrm{O}_{7}$ in the presence of NaPP. Furthermore, 
after adding NaPP, the P2p atomic concentration increased from $10.84 \%$ to $11.69 \%$, which also showed NaPP successfully chemisorbed onto the apatite surface, and thus depressed the flotation of apatite.

As for dolomite, the Ca2p and Mg1s peaks with and without NaPP are also fitted to confirm the chemical information of surface species. It could be seen from Figure $7 \mathrm{~b}$, the Ca2p peak of single dolomite appeared at $347.00 \mathrm{eV}$, in which the peak of $347.00 \mathrm{eV}$ was assigned to $\mathrm{CaCO}_{3}$. After the addition of $\mathrm{NaPP}$, a new $\mathrm{Ca} 2 \mathrm{p} 3 / 2$ peak for $\mathrm{Ca}_{2} \mathrm{P}_{2} \mathrm{O}_{7}$ was observed and the characteristic $\mathrm{P}$ was also detected on dolomite surface. However, the $\mathrm{Mg} 1 \mathrm{~s}$ binding energy did not change in the presence of NaPP. All these changes offered good evidence that NaPP adsorbed onto dolomite surface, and selectively reacted with active $\mathrm{Ca}$ sites rather than $\mathrm{Mg}$ sites.
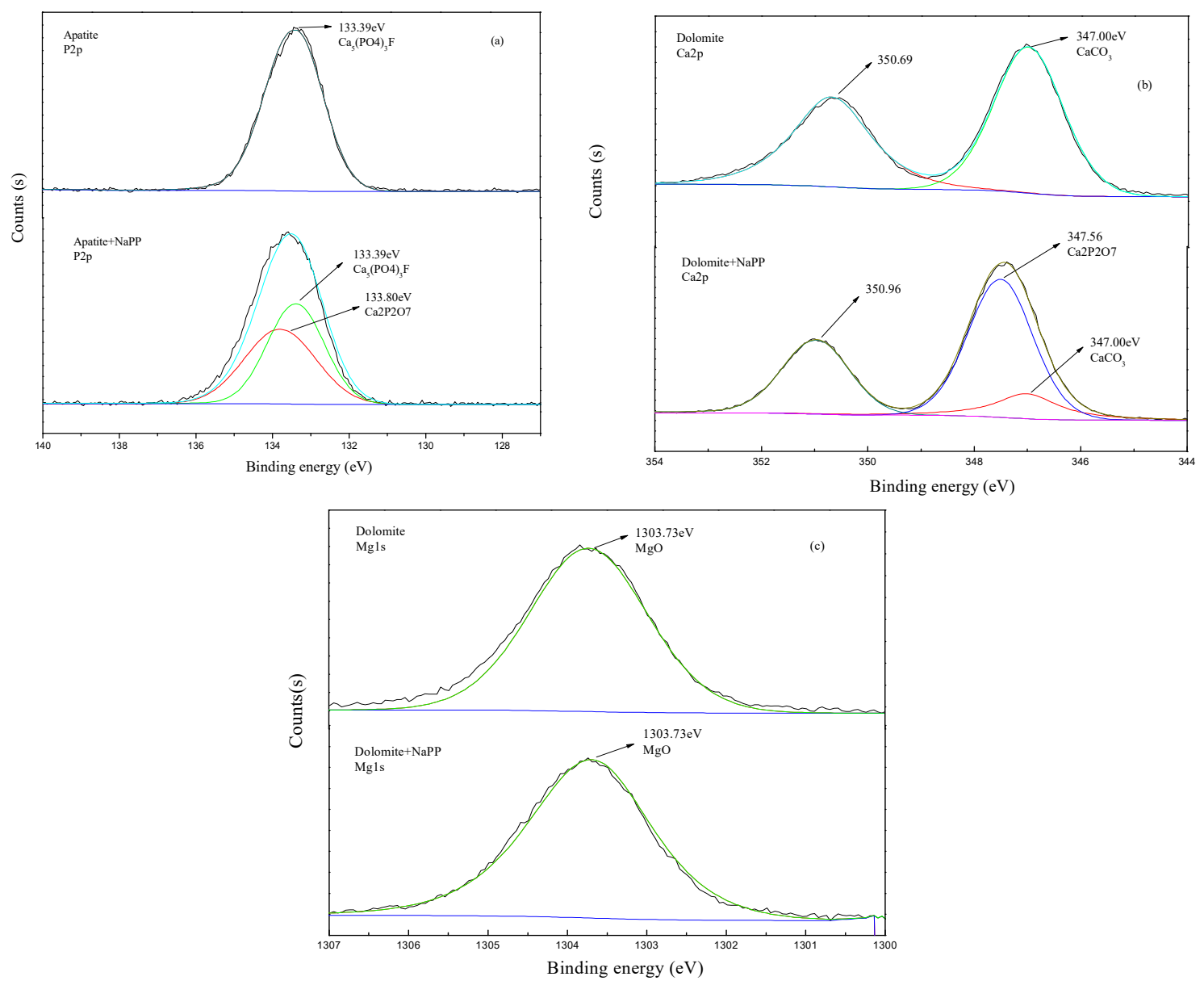

Figure 7. Fitting of X-ray photoelectron spectroscopy (XPS) spectra of (a) P2p of apatite, (b) Ca2p of dolomite and (c) Mg1s of dolomite before and after treatment with NaPP.

In addition, to obtain more detailed information about the selective depression of NaPP on apatite flotation, broad scan XPS analyses of apatite and dolomite under different reagent conditions were also employed, and the results are shown in Figure 8 and Table 2. Generally, an obvious shift of binding energy indicates variations of chemical environment. From Table 2 we can see that after apatite was treated with $\mathrm{NaOL}$, the binding energy of Ca2p decreased by $0.51 \mathrm{eV}$, which revealed a chemical interaction between apatite and NaOL. For the chemical adsorption of NaOL onto apatite surface, apatite was hydrophobic. After apatite was treated with both $\mathrm{NaPP}$ and NaOL, the binding energy of $\mathrm{Ca} 2 \mathrm{p}$ shifted by $0.05 \mathrm{eV}$, which was much smaller than that treated with single NaOL, indicating that the interaction between apatite and $\mathrm{NaOL}$ was obviously suppressed by NaPP. Meanwhile, according to Figure 7 we deduced that active Ca sites strongly interacted with both NaPP and NaOL. When 
$\mathrm{NaPP}$ was added before $\mathrm{NaOL}, \mathrm{NaPP}$ chemisorbed onto apatite surface and thus restricted the reaction of Ca with NaOL. Thus, the flotation of apatite was depressed by NaPP.

In the case of dolomite, after treatment with $\mathrm{NaOL}$, the binding energy of $\mathrm{Ca} 2 \mathrm{p}$ and $\mathrm{Mg} 1 \mathrm{~s}$ shifted by $-0.63 \mathrm{eV}$ and $-0.29 \mathrm{eV}$, respectively. These changes suggested that both $\mathrm{Ca}$ and $\mathrm{Mg}$ were active sites for chemical reaction with $\mathrm{NaOL}[5,25]$. Moreover, the shift of Ca2p binding energy of dolomite was larger than that of apatite, revealing that the interaction between $\mathrm{Ca}$ of dolomite and $\mathrm{NaOL}$ was more intensive, which was in accordance with the flotation results of Figure 3 and the contact angle measurements of Figure 6. Interestingly, after dolomite was treated with both $\mathrm{NaPP}$ and $\mathrm{NaOL}$, the binding energy of $\mathrm{Ca} 2 \mathrm{p}$ and $\mathrm{Mg} 1 \mathrm{~s}$ changed by $-0.07 \mathrm{eV}$ and $-0.56 \mathrm{eV}$, respectively. These results demonstrated that for dolomite both $\mathrm{Ca}$ and $\mathrm{Mg}$ were active sites that reacted with $\mathrm{NaOL}$. The presence of $\mathrm{NaPP}$ restricted the interaction between active $\mathrm{Ca}$ sites and $\mathrm{NaOL}$, but enhanced the interaction between $\mathrm{Mg}$ sites and $\mathrm{NaOL}$. Thus, $\mathrm{Mg}$ became predominant active sites for $\mathrm{NaOL}$ adsorption. Thus, these changes did not affect the adsorption of $\mathrm{NaOL}$ and maintained the flotation performance of dolomite with the addition of NaPP.
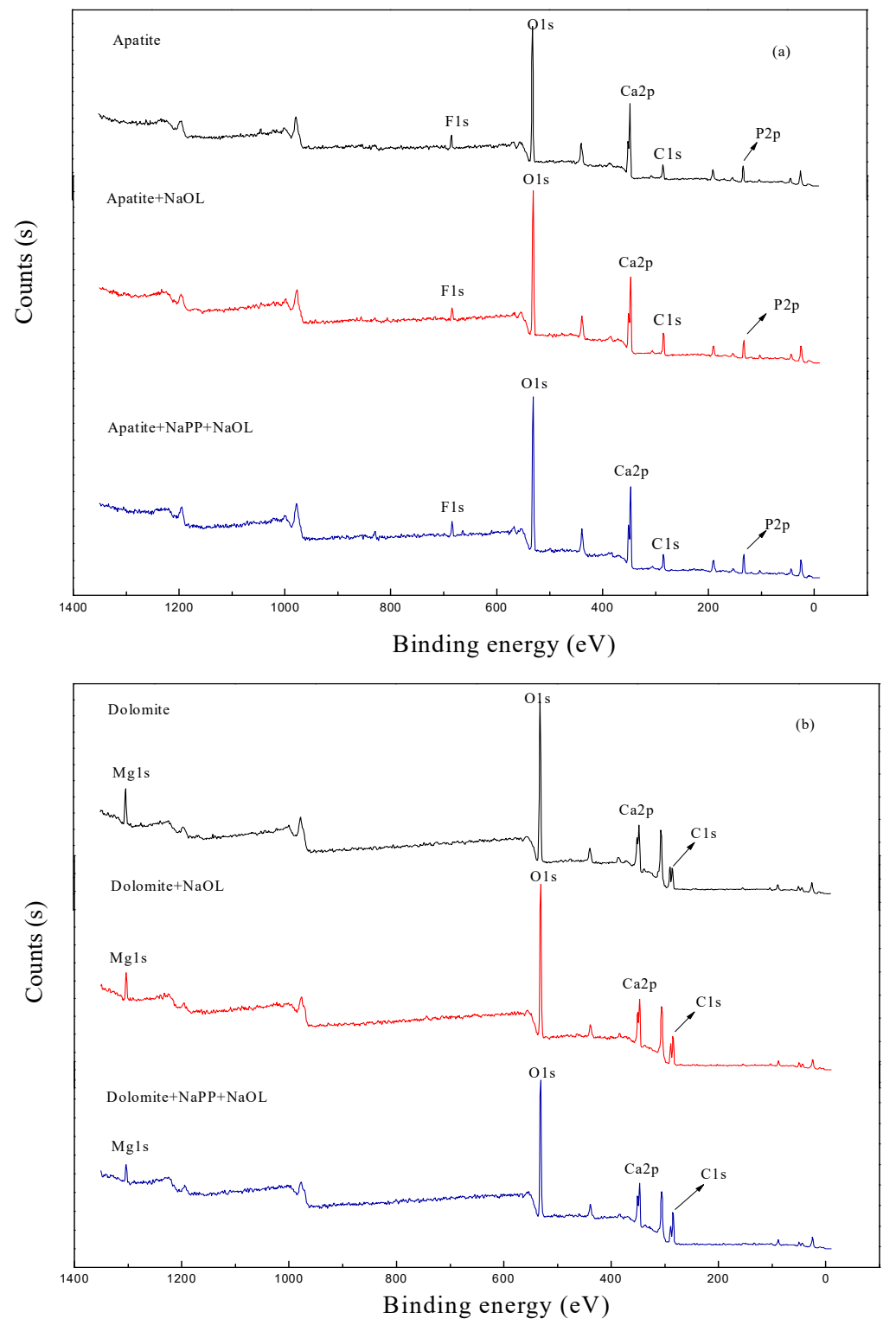

Figure 8. Broad scan XPS spectra of (a) apatite and (b) dolomite before and after treatment with NaPP or $\mathrm{NaPP}+\mathrm{NaOL}$. 
Table 2. Binding energy of elements on the minerals surface under different reagent conditions.

\begin{tabular}{ccccc}
\hline \multirow{2}{*}{ Sample } & \multicolumn{2}{c}{ Binding Energy (eV) } & \multicolumn{2}{c}{ Chemical Shift (eV) } \\
\cline { 2 - 5 } & Ca & Mg & Ca & Mg \\
\hline Apatite & 347.54 & - & - & - \\
Apatite + NaOL & 347.03 & - & -0.51 & - \\
Apatite + NaPP + NaOL & 347.49 & - & -0.05 & - \\
Dolomite & 347.14 & 1303.79 & - & - \\
Dolomite + NaOL & 346.51 & 1303.50 & -0.63 & -0.29 \\
Dolomite + NaPP + NaOL & 347.07 & 1303.23 & -0.07 & -0.56 \\
\hline
\end{tabular}

\subsection{Depression Mechanism of NaPP}

Based on the flotation results, zeta potential and contact angle measurements, and XPS analysis, the possible mechanism about NaPP depression is proposed in Figure 9.

For apatite, Ca provided the only active sites which interacted with both $\mathrm{NaPP}$ and NaOL. This led to the competitive adsorption of $\mathrm{NaPP}$ and $\mathrm{NaOL}$ onto apatite surface. The pre-adsorption of hydrophilic $\mathrm{NaPP}$ occupied active $\mathrm{Ca}$ sites, restricting the adsorption of $\mathrm{NaOL}$ onto apatite surface and thus producing hydrophilia in apatite. However, dolomite has both active $\mathrm{Ca}$ and $\mathrm{Mg}$ sites for chemical reaction with $\mathrm{NaOL}$. Thus, while $\mathrm{NaPP}$ interfered with the interaction of active Ca sites with $\mathrm{NaOL}$, it improved the reactivity of the $\mathrm{Mg}$ sites with collector. Thus, the interaction differences resulted in the selective depression of apatite by NaPP.

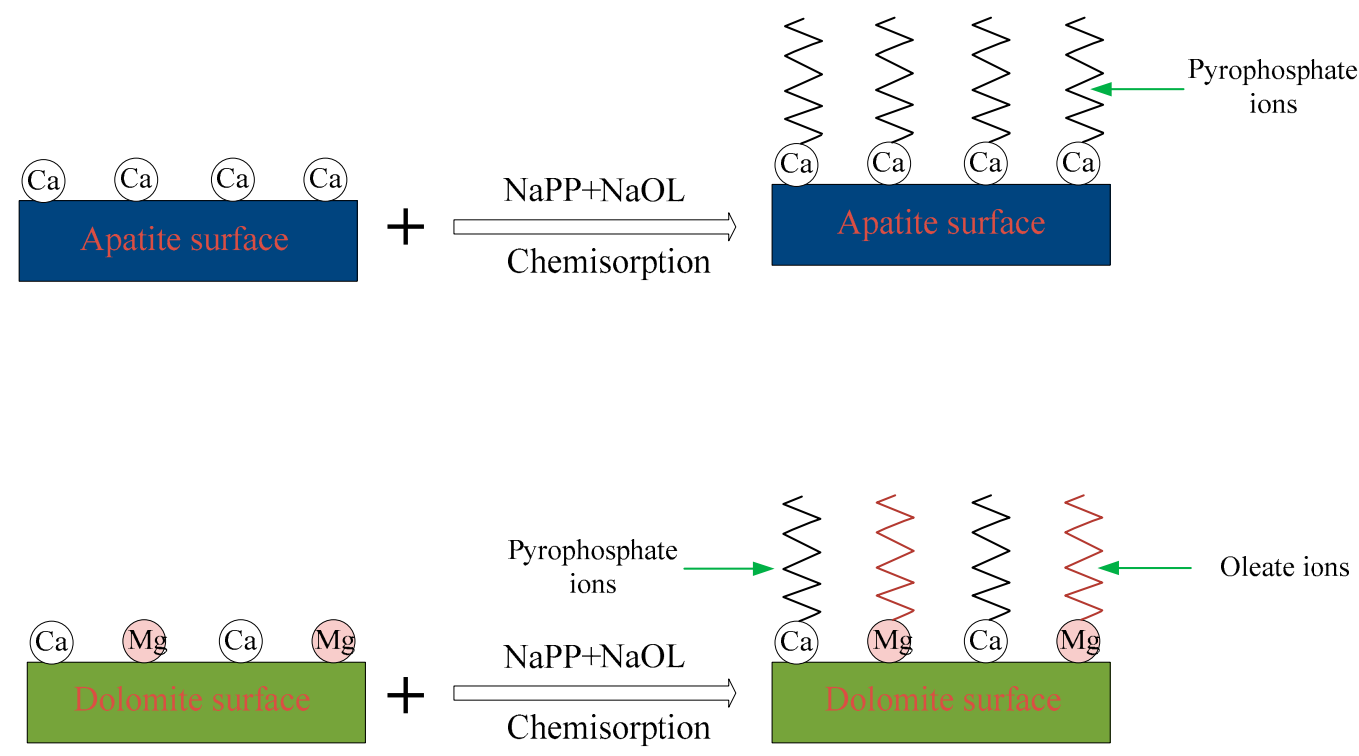

Figure 9. Schematic diagram of potential depression mechanism of NaPP.

\section{Conclusions}

This study systematically investigated the effect of sodium pyrophosphate on the selective reverse flotation of apatite from dolomite. NaPP showed selective depression of apatite, thus realizing the preferential flotation separation of apatite from dolomite. Based on the results of zeta potential and contact angle measurements, and XPS analyses, it was concluded that NaPP occupied active Ca sites and hindered the adsorption of $\mathrm{NaOL}$ onto apatite surface. As for dolomite, although the presence of $\mathrm{NaPP}$ interfered with the interaction between active $\mathrm{Ca}$ sites and $\mathrm{NaOL}$, it improves the reactivity of active $\mathrm{Mg}$ sites with $\mathrm{NaOL}$. Thus, the flotation of dolomite was slightly influenced by NaPP. In this way, the separation of apatite from dolomite was achieved. However, the limitation of the work is that 
the test was carried out on pure minerals. The focus of the following work is to confirm the results with dolomitic phosphate ores.

Author Contributions: Y.C. and G.Z. conceived and designed the experiments; Y.C. prepared the samples and performed the experiments; Q.F. and G.Z. contributed reagents/materials/analysis tools; Y.C. analyzed the data; Y.C., R.L., and D.L., wrote and revised the paper.

Funding: This research received no external funding.

Acknowledgments: This work was supported by the National Basic Research Program of China (2014CB643402).

Conflicts of Interest: The authors declare no conflicts of interest.

\section{References}

1. Cao, Q.; Cheng, J.; Wen, S.; Li, C.; Bai, S.; Liu, D. A mixed collector system for phosphate flotation. Miner. Eng. 2015, 78, 114-121. [CrossRef]

2. Helbig, C.; Baldauf, H.; Mahnke, J.; Stöckelhuber, K.W.; Schulze, H.J. Investigation of Langmuir monofilms and flotation experiments with anionic/cationic collector mixtures. Int. J. Miner. Process. 1998, 53, 135-144. [CrossRef]

3. Gharabaghi, M.; Irannajad, M.; Noaparast, M. A review of the beneficiation of calcareous phosphate ores using organic acid leaching. Hydrometallurgy 2010, 103, 96-107. [CrossRef]

4. Li, G.; Cao, Y.; Liu, J.; Wang, D. Cyclonic flotation column of siliceous phosphate ore. Int. J. Miner. Process. 2012, 110-111, 6-11. [CrossRef]

5. Dos Santos, M.A.; Santana, R.C.; Capponi, F.; Ataíde, C.H.; Barrozo, M.A.S. Effect of ionic species on the performance of apatite flotation. Sep. Purif. Technol. 2010, 76, 15-20. [CrossRef]

6. Liu, X.; Li, C.; Luo, H.; Cheng, R.; Liu, F. Selective reverse flotation of apatite from dolomite in collophanite ore using saponified gutter oil fatty acid as a collector. Int. J. Miner. Process. 2017, 165, 20-27. [CrossRef]

7. Abdel-Khalek, N.A. Evaluation of flotation strategies for sedimentary phosphates with siliceous and carbonates gangues. Miner. Eng. 2000, 13, 789-793. [CrossRef]

8. Mohammadkhani, M.; Noaparast, M.; Shafaei, S.Z.; Amini, A.; Amini, E.; Abdollahi, H. Double reverse flotation of a very low grade sedimentary phosphate rock, rich in carbonate and silicate. Int. J. Miner. Process. 2011, 100, 157-165. [CrossRef]

9. Zheng, X.; Smith, R.W. Dolomite depressants in the flotation of apatite and collophane from dolomite. Miner. Eng. 1997, 10, 537-545. [CrossRef]

10. Sis, H.; Chander, S. Reagents used in the flotation of phosphate ores: A critical review. Miner. Eng. 2003, 16, 577-585. [CrossRef]

11. Yu, J.; Ge, Y.; Guo, X.; Guo, W. The depression effect and mechanism of NSFC on dolomite in the flotation of phosphate ore. Sep. Purif. Technol. 2016, 161, 88-95. [CrossRef]

12. Li, X.; Zhang, Q.; Hou, B.; Ye, J.; Mao, S.; Li, X. Flotation separation of quartz from collophane using an amine collector and its adsorption mechanisms. Powder Technol. 2017, 318, 224-229. [CrossRef]

13. Amankonah, J.O.; Somasundaran, P. Effects of dissolved mineral species on the electrokinetic behavior of calcite and apatite. Colloids Surf. 1985, 15, 335-353. [CrossRef]

14. Elgillani, D.A.; Abouzeid, A.Z.M. Flotation of carbonates from phosphate ores in acidic media. Int. J. Miner. Process. 1993, 38, 235-256. [CrossRef]

15. Liu, X.; Ruan, Y.; Li, C.; Cheng, R. Effect and mechanism of phosphoric acid in the apatite/dolomite flotation system. Int. J. Miner. Process. 2017, 167, 95-102. [CrossRef]

16. Guimarães, R.C.; Araujo, A.C.; Peres, A.E.C. Reagents in igneous phosphate ores flotation. Miner. Eng. 2005, 18, 199-204. [CrossRef]

17. Hernáinz, F.; Calero, M.; Blázquez, G. Flotation of low-grade phosphate ore. Adv. Powder Technol. 2004, 15, 421-433. [CrossRef]

18. Vučinić, D.R.; Radulović, D.S.; Deušić, S.D. Electrokinetic properties of hydroxyapatite under flotation conditions. J. Colloid Interface Sci. 2010, 343, 239-245. [CrossRef] [PubMed]

19. Liu, X.; Luo, H.; Cheng, R.; Li, C.; Zhang, J. Effect of citric acid and flotation performance of combined depressant on collophanite ore. Miner. Eng. 2017, 109, 162-168. [CrossRef] 
20. Rashchi, F.; Finch, J.A. Polyphosphates: A review their chemistry and application with particular reference to mineral processing. Miner. Eng. 2000, 13, 1019-1035. [CrossRef]

21. Edwards, C.R.; Kipkie, W.B.; Agar, G.E. The effect of slime coatings of the serpentine minerals, chrysotile and lizardite, on pentlandite flotation. Int. J. Miner. Process. 1980, 7, 33-42. [CrossRef]

22. Chen, W.; Feng, Q.; Zhang, G.; Yang, Q.; Zhang, C.; Xu, F. The flotation separation of scheelite from calcite and fluorite using dextran sulfate sodium as depressant. Int. J. Miner. Process. 2017, 169, 53-59. [CrossRef]

23. Yongxin, L.; Changgen, L. Selective flotation of scheelite from calcium minerals with sodium oleate as a collector and phosphates as modifiers. I. Selective flotation of scheelite. Int. J. Miner. Process. 1983, 10, 205-218. [CrossRef]

24. Merma, A.G.; Torem, M.L.; Morán, J.J.V.; Monte, M.B.M. On the fundamental aspects of apatite and quartz flotation using a Gram positive strain as a bioreagent. Miner. Eng. 2013, 48, 61-67. [CrossRef]

25. Lu, Y.; Drelich, J.; Miller, J.D. Oleate Adsorption at an Apatite Surface Studied by Ex-Situ FTIR Internal Reflection Spectroscopy. J. Colloid Interface Sci. 1998, 202, 462-476. [CrossRef]

2018 by the authors. Licensee MDPI, Basel, Switzerland. This article is an open access article distributed under the terms and conditions of the Creative Commons Attribution (CC BY) license (http://creativecommons.org/licenses/by/4.0/). 